\title{
Human Capital and English Language Proficiency in the Chinese Context
}

\author{
Xiaoyu Luo ${ }^{1} \&$ Shawn P. Daly ${ }^{2}$ \\ ${ }^{1}$ International College, Hunan Institute of Engineering, Hunan, China \\ ${ }^{2}$ College of Business, Niagara University, New York, United States \\ Correspondence: Xiaoyu Luo, No.88, Fuxing Middle Road, Hunan Institute of Engineering, Xiangtan, Hunan, \\ China. Tel: 86-133-1732-5888. E-mail: cathyluo1981@gmail.com
}

Received: June 28, 2018 Accepted: July 7, $2018 \quad$ Online Published: February 28, 2019

doi:10.5539/ass.v15n3p73 URL: https://doi.org/10.5539/ass.v15n3p73

\begin{abstract}
The employment problem of college graduates has evoked concern around the world, which is particularly prominent in China in recent years. At the same time, English language proficiency of Chinese college students has been emphasized within their university academic requirements as well as from prospective employers. The consequent market pressure on Chinese college students to obtain language qualifications has created an environment where not only the utility, but also the symbolic value of English proficiency has become essential. Human capital theory describes the complex connection between language proficiency and employment, as a foreign language skill, English is similar to other human capital and has the potential for economic value. From the theoretical perspective for relationship between English language proficiency and employment of college graduates based on human theory, recommendations are made for further both scholarly research and practitioner policies, namely: National College English Teaching Syllabus, Regulations for Full-time Undergraduate Bachelor's Degree-granting, and Regulations for the Graduation Project.
\end{abstract}

Keywords: English language proficiency, China youth employment, human capital, symbolic value

\section{Introduction}

\subsection{Economic Necessity for the Asian Masses}

Decades of progress achieved by many countries in reducing poverty is under threat, with employment vulnerability playing a key role (Zhu \& Wang, 2016, August 26). The report of the 19th National Congress of the Communist Party of China (2017) describes how the employment problem has begun to negatively affect citizens' livelihood and is considered a significant social problem in China. Furthermore, the report also stresses prioritizing the national quality of education and enhancing Chinese economic growth. Local governments and universities have also promulgated a series of policies to promote the employment of college students.

Yet, youth employment is a particularly prominent problem in China. Since 1999, the Chinese government has promoted the expansion of higher education enrollment. In 2017, the number of college graduates in China reached 7.95 million, about seven times the 1.14 million graduates of 2011 (China Education Network, n. d.). While the new educational environment could extend national learning opportunities and promote economic development, it increases competition among Chinese college graduates to obtain employment after graduation. It is this enhanced stress that drives the characteristics of the employment market for graduates in China thereby creating fertile ground for job market characteristics which promote job prospects, but may not necessarily meet the needs of employers.

\subsection{Employment Opportunity in Human Capital}

Experts and scholars have long carried out studies regarding factors influencing college graduate employment (Chen \& Liu, 2015; Gonzalez, 2000; Huang, 2008). Some scholars have analyzed the situation of young college graduates in the labor market by examining the impact of gender (Potestio, 2011; Rotkowski, 2003). Chinese researchers have also considered contradictions between the training of higher education and the needs of economic and social development, job market and employer selection, student interests, and social structure (Chen, 2005; Li, 2017).

A prime conclusion from the foregoing studies is that labor forces with higher human capital obtain better 
employment opportunities and higher income. Human capital theory explains that education is a prime component of human capital investment, impacting employment and marginal productivity (Baptiste, 2001). This perspective indicates individuals' continuous investment in human capital through education and training is an important factor for determining chances for future employment. But human capital is derived from both direct utilitarian (achievement) and indirect value-based (ascriptive) factors. The ascriptive aspects include gender, appearance, and origin, etc., while the more directly value-based elements include specialty skills, learning ability, foreign language level, school reputation, and political outlook (Blau \& Duncan, 1967).

Many language economists believe the application of foreign language human capital brings economic value influenced by the law of supply and demand in the market economy (Diebolt, 2004; Drinkwater \& O'Leary, 1997). As a means to obtain this ability, learning English in college must be considered a human capital investment. Consequently, the importance of foreign language ability cultivation has been widely recognized by researchers as an important strategy for students to achieve employment outcomes (Grenier \& Xue, 2011; Neamțu, 2012).

Yet, there is evidence non-utilitarian value of language proficiency also plays a role in achieving employment. Group think effects from social psychology, via the "English craze", has long played an important role in the Chinese economy and society (Nong, 2009). That is, as English increases in popularity, proficiency achieves a psychological value beyond its utility. This "English fever" may waste Chinese educational resources by directing students away from their prescribed studies, even creating a culture with abnormal patterns of language usage, with English proficiency rising as an important entry point into professions (Zhang, 2014).

\subsection{Centrality of English Language Training}

English is one of the most frequently learned languages in the world. In 2015, 67 nations spoke English as the primary official language and 27 more counties used English as a secondary official language. At present, over 1.5 billion people speak English, of which 375 million are native speakers (The Statistic Portal, 2017). Roughly four hundred million Chinese students study English ("English language proficiency application," 2016). As the main foreign language in China and around the world, college English has become a basic public course for many non-English students upon entering university.

The influence of English on the employment of college students is mainly reflected in requirements that employees demonstrate English proficiency. Zhao (2004) maintained that the level of English language proficiency is an important factor affecting Chinese college students' employment competitiveness from his surveys in paper collected in Beijing, Guizhou and other major cities. Employers now examine pass rates of the CET-4 and CET-6 (College English Test, four and six years, respectively), and some have placed IELTS and TOEFL scores in their recruitment requirements. According to the National Long-term Education Reform and Development Plan (2010-2020) and the Several Opinions on Improving the High Education Quality (Ministry of Education, 2017), college education in a foreign language is an important part of higher education in China. As a result, language training is of significance for the coordinated development of college students' knowledge, ability, and comprehension quality.

Proficiency in English plays an important role in other Asian countries, as well. In Japan, most high schools only offer English courses because many Japanese universities utilize English as part of their entrance examinations (Ikegashira, Masumoto, \& Morita, 2009). In South Korea, government policies clearly outline the vital role English language proficiency plays in global competition for both individuals and the country (Chung \& Choi, 2016). Within Korean public schools, formal English lessons begin in third grade; even earlier for many private schools. Many non-English speaking governments around the world provide significant financial support and investment for English education (Cristal, 2001).

\section{Literature Review}

\subsection{Human Capital Theory}

According to Schultz (1961), human capital is acquired by workers as the total sum of knowledge, health status, and level of education. Such skills are obtained through investment in education, training, health care, labor migration, and employment information (Baptiste, 2001). Human capital theory thus provides the vital link between education and economic growth, emphasizing the value of investing in human capital (Baptiste, 2001; Diebolt, 2004). Later, Becker applied a utility-maximizing approach for calculating the rates of return between education and human capital. He believed school and college education would significantly increase labor income due to the economic benefit of schooling (Stanfield, 2009).

Becker (1964) divided individual skills into special skills and common skills, and extended human capital 
investment from the individual to the organizational level. That is, the organization's investment in the training of individual general skills impacts productivity of both the individual and organization. Generalized skills thus can play key roles in a variety of organizations with relatively high portability and substitutability. In contrast, the substitutability and portability of special skills, particular to the organization, were relatively weak and could only achieve the improvement of individual productivity in certain organizations. Theorists of human capital theory also argued that policy makers need to distinguish generalized from specialized skills, while considering the mode of investment (Kessler \& Lülfesmann, 2006). In summary, some skills investments may increase personal income via human capital, while not realizing value for organizations and society.

\subsection{Human Capital Effects and the Empirical Literature}

\subsubsection{What Relationship Is There Between English Language Proficiency and Human Capital?}

A positive relationship between English language proficiency and human capital is supported by the literature (Chiswick \& Miller, 2002; Evans, 1989; Vaillancourt, 1982; Zhang, 2014). Chiswick and Miller (2002) observed that English language proficiency meets human capital requirements. Wang (2015) studied human capital and found that it was affected by language. Many scholars have observed English language proficiency to be a central component of human capital (Chiswick \& Miller, 2002; Evans, 1989; Wang, 2015; Zhang, 2014).

\subsubsection{To What Degree Does Human Capital Impact Employment?}

Empirical studies have demonstrated that college students with rich internship experiences increase employment opportunities and raise working efficiency after graduation (Meyer \& Wise, 1979; Sagen, Dallam, \& Laverty, 2000). Focusing on scholars who have studied China, Meng, Su and Shi (2012) found that college students who want to increase the probability of direct employment must work hard to expand their width and breadth of human capital. Dong and Xue (2014), in their graduates' survey conclude that academic achievement of graduates had a significant and positive impact on their employment. Liu (2015) studied colleges in Hubei Province to explore the relationship between human capital and employment, which also showed a significant result between human capital and employment as well. Similarly, Yue, Wen, and Ding (2004) concluded that human capital affects employment directly.

\subsubsection{To What Degree Does English Language Proficiency Impact Employment?}

The majority of scholars have concluded through empirical research that English language proficiency affects employment positively (Chiswick \& Miller, 2010; Dustmann \& Fabbri, 2003; McManus, Gould, \& Welch, 1983; Tainer, 1988). McManus et al. (1983) revealed that immigrants' English language proficiency had a greater impact on technical positions than other positions in the labor market. Daly (2012) found that for Mexican immigrants, English language proficiency strongly increased earnings, particularly near the border with the United States. Zhao (2004) discovered that the employment rate for students who passed CET-4 was about 15\% higher than those who had not. Huang (2008) showed that by the passing CET-4, college students would have $2.73 \%$ higher employment rate.

\subsection{Link between Human Capital and English Language Proficiency}

In human history, there has always been a very close relationship between economic activities and language development. Smith (1776) described the origin and development process of language conforming to the market principle of the "invisible hand". Friedman (1953) believed the spontaneous formation process of language and of markets was similar. Marchak (1965) revealed the economic value of language as an indispensable human tool, having economic attributes just like many other resources: value, utility, cost and benefit.

Vaillancourt (1982) pointed out that obtained knowledge and skills through work experience and formal education of mathematics, history, and English were components of human capital. He also discussed economics studies with the allocation of scarce resources among competing individuals. Such resources may be obtained with a certain price, through investment of time and capital cost, all of which expected to generate returns, including higher incomes, lower costs and a larger social network. Zhang (2014) stated that language learning itself, especially foreign language learning, is a central component of human capital investment.

Dhir (2005) believed that the economic value of language, both in macro and micro aspects, could be realized through its use. The economic values in macro aspect were mainly reflected in the language's position within the social lives of different ethnic groups, use frequency, emotion, and related language policy (Waldorf et al., 2010). Since the late 1960s, Breton (1978) took the lead in starting economics' study of bilingual and multilingual phenomena, analyzing economic status and income gap among different ethnic immigrants caused by their language factor. The micro economic value of language was mainly reflected in the positive role and impact of the language ideographic function of people's communication behavior. As a result, people were urged to do the 
corresponding economic behaviors that met their expected needs (Chiswick \& Miller, 2003). The use of specific language on various occasions in different areas is the embodiment of this kind of micro economic value. Lazear (1995) believed that, through language learning, individuals would have more opportunities to communicate expanding social networks and more fully integrating into their local society, thus obtaining more employment opportunities.

With the development of economic globalization and integration, English as a "world language" occupies an important position in the political and economic activities of various countries (Wang, 2015). According to Chiswick and Miller (2002), English language proficiency has the property of production factors meeting the human capital requirements in three areas. First, English skills can be obtained through learning, vocational training, and other social activities. Second, the great amounts of time, energy, and money to obtain English skills are considered in terms of costs, benefits, and utility. Third, the positive factors of the English proficiency level of individuals in the labor market are quite salient (Chiswick \& Miller, 2002).

Wang (2015) concluded that human capital is affected by language, emphasizing the economic value of language. He explained that acquisition of English language proficiency requires direct and indirect costs, especially the opportunity cost of time. Therefore, if language learners spend their language learning time on other tasks the learners achieve different levels of ability (Wang, 2015). According to Dustmann and Fabbri (2003), an employee could obtain different economic benefits and thereby have a certain market value provided that the language learned meets the requirements of their labor market. A Chinese scholar, Yin (2010) observed that as an investment of human capital in a specific form, English learning will naturally produce economic benefits. Yin further explained that English language has potential economic value similar to other human capital, obtained through investment and accruing profits through the application of English language.

Other human capital scholars have considered the cultural attributes of language (Lazear, 1995). For example, by utilizing qualitative and cross-culture research methods, Milken and Mohamed (2014) determined that English language proficiency could be considered as a form of cultural capital, which has become associated with symbolic values. That is, speaking fluent English becomes a demonstration of high social status, increasing the attributed human capital of the speaker. Piche, Renaud, and Gingras (1999) demonstrated that the individual education return rate in emerging industry is higher than in other relatively mature industries. They believed that this was a result of better education and study abilities of individuals who engaged in the emerging industry. Such individuals are more adaptable to technological changes, and therefore, they have the potential to obtain a higher income. In other words, they gain a greater understanding of the industry, another manifestation of cultural capital.

\subsection{Link between Human Capital and Employment}

As described earlier, Blau and Duncan (1967) divided individual human capital in American society into ascriptive factors and achievement factors. In their empirical studies, Blau and Duncan (1967) demonstrated that ascriptive factors and achievement factors influence individual employment interdependently. Achievement factors are acquired by the individual through formal or informal education and vocational training. Ascriptive factors are inherited, including most importantly, the individual's paternal education level and occupational status. In this view, during college students' job-seeking process, human capital becomes the cornerstone of success, whereas social capital is the bridge to identify holders of human capital.

Schultz (1963) opined that human capital is embodied in the labors' degree of knowledge, technical level, job skills and health, and specific human capital investment is the comprehensive value of those aspects. Becker (1964) found human capital being closely related to employment because human capital is associated education investments, job experience and skills, increasing labor market results (Byoun, 2013, p. 27).

Scholars have also used various other models to prove that people with higher human capital have spent less time in finding jobs (Akram \& Nymoen, 2006; Riddell \& Song, 2011; Saito \& Wu, 2016). Huang (2008) proposed an employability hypothesis based on human capital. Meng et al. (2012) explained a view that college students who want to increase the probability of direct employment must work hard to expand their width and breadth of human capital, as well as be aware of the network of human capital contributors. This idea was developed based on the changing circumstances of China's labor market transition since 2008.

Consequently, many scholars concluded that people would achieve economic benefits through language by engaging in various kinds of occupational activities based on human capital theory. The higher level of proficiency in foreign languages will generate higher economic benefits. Employers would provide people with better working conditions and income (Chiswick \& Miller, 2002; Espenshade \& Fu, 1997; Shields \& Wheatly, 2002). 


\subsection{Link between English Language Proficiency and Employment}

The basic attribution of language as a foundation of the relationship between language skills and employment in economics is based on two perspectives. One perspective is to consider language as the carrier of culture, and identify the effects of language skills on individual employment by social discrimination or identification (Lazear, 1995). The cultural attribute of language is able to produce a type of identity recognition among people who speak the same language (Espenshade \& Fu, 1997). Meanwhile, language difference from different groups causes gaps and friction in communication, leading to lower cultural identity and alienation between different groups. Based on the cultural attribute of language, Lazear (1995) created a model to focus on the individual language learning orientation, the relationship between the population scale and the social integration. He believed that, through language learning, individuals could have more chances of communication to expand social networks and to better integrate into local society, thus obtaining more employment. In the labor market, people who spoke a principal language would gradually alienate the people who used non-principal languages (Grenier, 1989). Identity discrimination resulted in non-principal language groups becoming marginalized in the labor market which formed labor market segmentation. This played an adverse effect on employment for minorities (Chiswick \& Miller, 2010; Drinkwater \& O’Leary, 1997). Toussaint-Comeau (2006) in a study of Hispanic immigrants in the U.S., stated that those with a language proficiency in English had higher occupational status than those who did not speak English. Taken together, these studies point to the importance of maintaining social networks and the role English language may have in creating such relationships.

Another research perspective of the relationship between language and employment included a human capital lens (McManus et al., 1983; Tainer, 1988) which regarded language skills as an external representation of individual ability; a signaling (Chiswick \& Miller, 2008). This economic value of language was affected by supply and demand in a job market, leading to a scarcity valuation of language proficiency (Boyd, 1992). Lang (1986) analyzed the segmentation of the labor market based on the perspective of language differences and created a model based on the human capital attribute of language influence on the mechanism of employment. He suggested that language differences between different groups led to the production of communication costs, thus forming a division of the labor market. Because of the cost of language learning, the group that used non-principal language had to accept the division of the labor market (Lang, 1986). In addition, the extremely competitive Asian employment markets foster student differentiation that may be more related to sociocultural values than to educational value as expressed by knowledge, skills, or abilities (Chung \& Choi, 2016).

\subsection{Direct Value of English Language Proficiency}

As an external representation of individual ability, the degree of language ability reflects individuals' productivity (Budría \& Swedberg, 2015; Thomsen, Gernandt, \& Aldashev, 2009). Enterprises or employers may infer an employee's ability from the individual's language competency by waiving the possible adverse influence of language-led alienation and discrimination in the labor market, guaranteeing their employee's job opportunity and income (Chiswick \& Miller, 1995; Dustmann \& Fabbri, 2003).

Since English plays an essential role in the education system in China, Chinese people have become more enthusiastic in English learning. Increasing numbers of Chinese scholars studied the influence of English language proficiency on employment and identified significantly greater employer's requirements of English ability by the job seekers (Du \& Yue, 2010; Qiao, Song, Feng, \& Shao, 2011; Yue, Wen, \& Ding, 2004). Lv (2011) surveyed on the employment status and university English learning situation among university graduates in Liaoning Province in 2010. He discovered that many of the employers had a clear statement on graduates' English level requirement.

Zhao (2004) observed that the employment rate for students who have passed CET-4 and CET-6 is higher than those who have not passed the test. English proficiency affects employment location selection (Zhao, 2004). For example, Beijing and other major cities have considered passing CET-4 as a basic requirement if graduates want to stay in the city for employment. The salary of college students who passed the CET-6 is $4.5 \%$ greater than their counterparts who did not (Wang, Smyth, \& Cheng, 2017). Major employment units such as foreign companies, large enterprises, and scientific research units have required high foreign language proficiency (Zhao, 2004).

\subsection{Other Concerns About Language Training}

But there are yet other reasons to consider why English language training may not achieve economic growth for the China people. First, the objectives of English language teaching are strictly based on comprehensive English language proficiency required in the National College English Teaching Syllabus (2007). As such, Chinese university curricula system cannot adapt to social needs - and therefore, there may be gaps between current job 
market requirements and the English language proficiency objectives of English education for students.

For example, demand for English in Chinese labor markets is concentrated on pursuing applied language abilities. However, the training objective of English language proficiency in many universities and colleges stays in a traditional research teaching model, which may lead to a conflict of educational characteristics. Particularly critical may be the possibility that their teaching methods and contents may deviate seriously from actual situations.

In addition, perhaps inappropriate English language proficiency is stipulated in promotion and job hunting. Many Chinese companies require college graduates to have CET- 4 and CET-6 certificates for any position. Consequently, most universities and colleges choose a single set of unified English materials for all non-English major students, and implement a single policy requiring the CET-4 for a bachelor's degree. This simplified mandate may be harmful to the development of science and culture, while adding to issues of hiring that emanate from inappropriate metrics.

Second, due to great advocacy by the State, English language teaching plays a very important role in the current institutionalized education. English language learning and examination taking are mandatory from Chinese junior middle school to senior professional title assessments. Yet, some colleges and universities may lack clear and definite cultivating objectives for their College English courses. In turn, many graduates have no clear awareness of how to define English proficiency before their job hunt.

In addition, many have commented on the low means of students taking the CET-4 (Liu, 2013). This reflects the poor level of students' performance in English in general. As a result, college students may pass the CET-4 and possibly even the CET-6, but lack fluent English speaking ability and English applied competence. Therefore, the talents cultivated with the current English language teaching mode in Chinese universities and colleges even deviate from the level of English language proficiency demanded by the testing system. Internal reasons may play a role; often, college English teachers may lack practical experience themselves. Relevant departments may also ignore professional needs, adopt compulsory English testing, violating teaching rules, and causing a waste of social and educational resources.

Moreover, curricula and systems capable of responding to new situations need to be established. The structures of the CET-4 test as well as the Academic English test are in four sections, including writing, listening, reading and translating. English education in China focuses on cultivating students' basic skills, such as listening, speaking, reading, writing and translation as per the guidelines in the National College English Teaching Syllabus (2007). Currently, College English curricula arrangement for non-English majors are operated by a unified two-year education model. The model is restricted by a lack of teaching material which impacts negatively on the students who require multi-level English language proficiency in order to join the job market. Present language acquisition policies create mechanized and formulated teaching and ignore the inner interest of the English learner. However, the central government did promulgate a series of policies to try to change and promote English education. Some specialized courses are required in bilingual teaching in order to improve students' language skills and related professional abilities, in addition to College English and Academic English. However, rapid development of Chinese society has determined that the goal of English talent cultivation and the corresponding curricula may need to stay dynamic.

\section{Conclusions}

Many employers require graduates have strong English language skills prior to hiring. To support the rapid development of Chinese society, higher requirements are being placed on the cultivation of English language talents. English learning for Chinese students who attend various occupational examinations require a huge investment of time and money. Chinese parents and students spend about $\$ 60$ billion a year just for English language teaching. It reports that $56 \%$ of non-English major students spend much of their time on English learning (Chinese News Net, 2013, Oct 18). This implies lessons for learning the English language accounts for a large portion of educational resources and some of these investments may not be particularly effective in promoting employment growth. However, the present review identified reasons why English language proficiency leads to success in the job market, but perhaps less directly to achievement in the workplace itself. That is, English proficiency's symbolic and networking value to student job seekers. The Chinese English education system may need to work towards responding to these dynamic demands placed on English language proficiency.

\subsection{Recommendations}

The findings of this review supports other studies which suggest rethinking English education in China and how 
to best promote employment of college graduates (Hu, 2015; Li, Morgan, \& Ding, 2008). The training of many students in English language proficiency has made great contributions to China's economic growth, social development, and cultural exchanges for many years. Clearly, English language proficiency has both utility and symbolic impacts on the employment outcomes. As such, various stakeholders in Chinese society may need to reflect on the problems associated with teaching English in Chinese universities.

\subsubsection{Higher Education}

The requirements of China's rapid industrial development should be met by the quality, knowledge, and competence of graduates. But the existing teaching system displays contradictions between market demand and development objectives. As suppliers of the labor market, Chinese colleges and universities may need to establish mechanisms more closely related to societal demands. According to new employer requirements of English language proficiency, institutions may need to re-examine the direction and strategy of English language teaching for training English language talent.

In College English courses, increased content directly related to employment and reformed teaching styles are indicated. Moving beyond the single traditional lecture-based teaching style, experiential learning may be added (Zein, 2017). For example, various employment scenarios may be presented to students to simulate real job market competition environments, allowing them practical use of their English language abilities. In addition to improving their competitive power in the marketplace, this will help to improve their interest in learning English.

Further, educators and administrators of universities and colleges may also need to take note of the importance of profession-specific abilities. To enhance students' learning initiative, specialty course teachers should strengthen professional education in specialty courses. Colleges and universities develop students' professional qualities, professional and social abilities, and problem-solving abilities. In other words, universities and colleges should strive to help students accumulate human capital so they are better equipped to respond to the demands of the labor market.

Institutions also should assist students change their perspectives regarding employment to gain more realistic employment expectations. University career centers may need to carry out a series of guidance courses and implement one-on-one coaching. These may help college students become aware of employment situations, build confidence, and establish positive attitude. To enhance the knowledge transfer, career centers at colleges and universities may provide information on employment, various forms of career guidance, and labor market predictions. They may need to also emphasize consultant and employment information services which do a better job with helping college students choose their major so that students are placed in a position to succeed right from the start.

\subsubsection{Government}

At the same time, government also may need to more systematically monitor how universities implement new programs and services. However, the regulation and reform of English education cannot be made with a "one size fits all" mentality. English examinations cannot be cancelled, nor English study ignored. The intent of reform is not to cancel English examinations or eliminate English language study. A primary goal for English education should be to promote employment effectiveness, as well as competitiveness of graduates.

In addition, it is recommended the Chinese government play a core role in creating a more cooperative atmosphere between higher education and enterprise. Related governmental departments should timely publicize the demands information of employment and foster information feedback between organizations and higher education. The government may need to develop job information networks in an official manner to achieve nationwide connectivity. This may help to promote employment and avoid the spread of misleading information about the content and value of English language proficiency.

\subsubsection{Organizations}

Enterprises choose selection criteria to recruit college students. Many of these selection criteria follow traditional styles in that they require English certification for every candidate in every position. For example, the policy of English language proficiency does not need to be rigid in the fields of non-English majors. According to their employment data, many companies set English language proficiency as a screening threshold of employment. However, it is suggested that policymaking may need to be made more nuanced in different fields so that the restrictions on the English language proficiency for the non-English major personnel or candidate, be reduced or exempted.

However, as shown in the present review, English language proficiency may not always have directly impact employment. Therefore, it is recommended that if a given career does not actually require English language 
proficiency, enterprises should not focus too much on language, since these investment heavy skills would not help students much. Instead, enterprises may need to screen potential employees based on their professional skills and experiences developed during their college study.

\subsubsection{Students and Families}

Human capital of college students has a positive impact on their employment. Consequently, college students must try their best to strengthen their practical ability, enrich their professional ability, and enhance their individual worth. Only by developing their professional skills through study are college students able to improve their own comprehensive qualities, enabling them to adapt to a continuously changing environment.

But to promote the healthy development of English language learning and teaching, it is necessary that the status and role of English education in school and society be understood and implemented throughout society. Presently there is a phenomenon of blind pursuit for English language certification by potential job applicants in China. Families should try to understand the "English craze" for its symbolic rather than utilitarian value.

\subsection{Further Research}

The present study has discovered a number of reasons that Chinese English language outcomes could be improved, based on human capital theory and empirical validation. One might say that in creating job outcomes, human capital is the foundation and social capital is supplementary. This amounts to a proposition that should be examined empirically: is social capital be a moderating variable (without it, human capital can't effectively function) or is it a mediating variable (with an implication that social capital might be an outcome of human capital investments).

Therefore, this process will require building social and cultural capital models. Some have called very recently for bringing a Bourdieusian philosophy to the study of Chinese higher education (Yu, 2018). As outlined above, as better students make their outstanding English proficiency manifest to all, speaking English takes on a strong symbolic, segmenting aspect (Choi, 2003). Bourdieu's cultural capital and social capital both play roles in students' employment success (Daly, 2012). Therefore, bringing human capital and social/cultural capitals into a single nomological model would bring clarity to understanding how English language proficiency impacts job outcomes.

A central outcome from this work is the primacy of human capital in studying English language proficiency. Different dimensions have been identified in the literature, including achievement and ascriptive, micro and macro, cultural and social. The balance among them in determining outcomes may allow for changing policies and individuals requirements. For instance, if the segmentation impact is most important, perhaps English language training might take on a more culture-intensive nature, rather than the employment-driven utilitarian aspects of language proficiency.

\section{Acknowledgments}

This work was supported by the Hunan province education scientific research project under Grant No. 15B058 and the Social and Science Fund of Hunan Province (No. 16WLH07).

\section{Notes on contributors}

Xiaoyu Luo is associate professor at International Education College, Hunan Institute of Engineering, China. She received her Ph.D. from Niagara University in the United States, and got her master degree from Brunel University in the UK. Her research interests center on English education in higher education, linguistic economics and quantitative research.

Shawn P. Daly is professor of international business and former dean of the College of Business Administration at Niagara University in the United States. His research interests center on application of Bourdieusian theory to education, behavior, and international development, especially in the Chinese context.

\section{References}

Akram, Q. F., \& Nymoen, R. (2006). Econometric modelling of slack and tight labor markets. Economic Modelling, 23(4), 579-596. https://doi.org/10.1016/j.econmod.2006.03.001

Baptiste, I. (2001). Educating lone wolves: Pedagogical implications of human capital theory. Adult Education Quarterly, 51(3), 184-201. https://doi.org/10.1177/074171360105100302

Becker, G. S. (1964). Investment in human capital: A theoretical analysis. Journal of Political Economy, 70, 9-49. https://doi.org/10.1086/258724

Blau, P. M., \& Duncan, O. D. (1967). The American Occupational Structure. New York: Wiley. 
Boyd, M. (1992) Gender issues in immigration and language fluency. In B. R. Chiswick (Ed.), Immigration, language, and ethnicity: Canada and the United States. Washington, DC: American Enterprise Institute.

Breton. A. (1978). Nationalism and language polices. Canadian Journal of Economics, 11(4), 656-668. https://doi.org/10.2307/134371

Budría, S., \& Swedberg, P. (2015). The impact of language proficiency on immigrants' earnings. Revista De Economía Aplicada, 23(67), 63.

Byoun, S. J. (2013). The impact of human capital and social capital on employment conditions of immigrants in the United States: An examination of gender and racial/ethnic differences. ProQuest Dissertations Publishing.

Chen, H. P. (2005). The study for the effect of human capital, social capital and the employment of college graduates on employment. Youth Studies, 11. In Chinese.

Chen, L. P., \& Liu, S. L. (2015). The impact of English language proficiency on college students' employment under the perspective of human capital. Youth Studies, 11, 404. In Chinese.

China Education Network. (n. d.). The number of graduates in China from 2001 to 2015. Retrieved from http://www.eol.cn/html/c/2016gxbys/

Chinese News Net. (2013, October 18). One-third Chinese people learn English and spend $\$ 60$ billion one year. Retrieved from http://edu.163.com/13/1018/18/9BG5G6SK00294IJF.html

Chiswick, B. R., \& Miller, P. W. (1995). The endogeneity between language and earnings: International analyses. Journal of Labor Economics, 13(2), 246-288. https://doi.org/10.1086/298374

Chiswick, B. R., \& Miller, P. W. (2002). Immigrant earnings: Language skills, linguistic concentrations and the Business cycle. Journal of Population Economics, 15(1), 31-57. https://doi.org/10.1007/PL00003838

Chiswick, B. R., \& Miller, P. W. (2008). A test of the critical period hypothesis for language learning. Journal of Multilingual and Multicultural Development, 29(1), 16-29. https://doi.org/10.2167/jmmd555.0

Chiswick, B. R., \& Miller, P. W. (2010). Occupational language requirements and the value of English in the US labor market. Journal of Population Economics, 23(1), 353-372. https://doi.org/10.1007/s00148-008-0230-7

Chiswick, B., \& Miller, P. W. (2003). The complementary of language and other human capital: Immigrant earnings in Canada. Economics of Education Review, 22(5), 469-480. https://doi.org/10.1016/S0272-7757(03)00037-2

Chung, J., \& Choi, T. (2016). English Education Policies in South Korea: Planned and Enacted. In R. Kirkpatrick (Ed.), English Language Education Policy in Asia. Language Policy, 11. https://doi.org/10.1007/978-3-319-22464-0_13

Daly, C. M. (2012). Immigration and Education: Setbacks and Opportunities for Earnings along the Texas-Mexico Border. Journal of Borderlands Studies, 27(3), 287-298. https://doi.org/10.1080/08865655.2012.750951

Dhir, K. S. (2005). The value of language: Concept, perspectives, and policies. Corporate Communications: An International Journal, 10(4), 358-382. https://doi.org/10.1108/13563280510630151

Diebolt, C. (2004). Towards a comparative economics of education. Compare, 34(1), 3-13. https://doi.org/10.1080/0305792032000180433

Dong, K. Y., \& Xue, Z. X. (2014). The impact on employment by human capital accumulating for college graduates. Chinese Public Administration, Vol. 6. In Chinese.

Drinkwater, S. J., \& O'Leary, N. C. (1997). Unemployment in Wales: does language matter? Regional Studies, 31(6). https://doi.org/10.1080/00343409750131712

Du, G. Y., \& Yue, C. J. (2010). Research on influence resources on employment opportunity of college graduates. Chinese higher education research, 11, 67-70. In Chinese.

Dustmann, C., \& Fabbri, F. (2003). Language proficiency and labor market performance of immigrants in the UK. The Economic Journal, 113, 695-717. https://doi.org/10.1111/1468-0297.t01-1-00151

Espenshade, T. J., \& Fu, H. (1997). An analysis of English-language proficiency among U.S. immigrants. American Sociological Review, 62(2), 288-305. https://doi.org/10.2307/2657305 
Evans, M. D. R. (1989). Immigrant entrepreneurship: Effects of ethnic market size and isolated labor pool. American Sociological Review, 54, 950-962. https://doi.org/10.2307/2095717

Friedman, M. (1953). The methodology of positive economics. In M. Friedman (Ed.), Essays in Positive Economics (pp. 3-43). Chicago, IL: University of Chicago Press.

Gonzalez, A. (2000). The acquisition and labor market value of four English skills: New evidence from NALS. Contemporary Economic Policy, 18(3), 259-269. https://doi.org/10.1111/j.1465-7287.2000.tb00023.x

Grenier, G. (1989). The effects of language characteristics on the wages of Hispano-American males. Southwest Journal of Business \& Economics, 6(4), 21.

Grenier, G., \& Xue, L. (2011). Canadian immigrants' access to a first job in their intended occupation. International Migration and Integration, 12, 275-303.

Hu, G. (2005). English language education in China: Policies, progress, and problems. Language policy, 4(1), 5-24. https://doi.org/10.1007/s10993-004-6561-7

Huang, J. B. (2008). Employment ability and college students' employment: A perspective of human capital theory. Beijing, Business management publication. In Chinese.

Ikegashira, A., Matsumoto, Y., \& Morita, Y. (2009). English Education in Japan - From Kindergarten to University. In R. Reinelt (Ed.), Into the Next Decade with (2nd) FL Teaching Rudolf Reinelt Research Laboratory EU Matsuyama, Japan (pp. 16-40).

Kessler, A. S., \& Lülfesmann, C. (2006). The theory of human capital revisited: On the interaction of general and

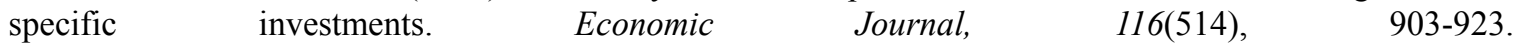
https://doi.org/10.1111/j.1468-0297.2006.01116.x

Lang, K. (1986). A language theory of discrimination. The Quarterly Journal of Economics, 101(2), 363-382. https://doi.org/10.2307/1891120

Lazear, E. (1995). Culture and language. NBER Working Paper No. 5249. https://doi.org/10.3386/w5249

Li, F., Morgan, W. J., \& Ding, X. (2008). The expansion of higher education, employment and over-education in China. International Journal of Educational Development, 28(6), 687-697. https://doi.org/10.1016/j.ijedudev.2007.10.002

Li, Y. L. (2017, July 5). CET 4 and CET 6 will lost the monopoly position in China. China Youth Daily. Retrieved from http://zqb.cyol.com/html/2017-07/25/nw.D110000zgqnb 20170725 4-02.htm

Liu, G. H. (2013). Chinese foreign language education: The empirical study based on language skills rate of return (Doctoral dissertation). Shandong University, Retrieved from http://xueshu.baidu.com/s?wd=paper uri\%3A\%2852cc452817dde0e090bd08e76f92f14b\%29\&filter=sc_long_sign\&tn=SE_xueshusource_2kduw 22v\&sc_vurl=http\%3A\%2F\%2Fcdmd.cnki.com.cn\%2FArticle\%2FCDMD-10422-1013220399.htm\&ie=utf $-8 \&$ sc_us $=11904172047188832446$

Liu, S. C. (2015). The case study of colleges in Hubei province for exploring the influence employment by human capital. Political \& Economy, 9-10. In Chinese.

Lv, J. J. (2011). A field investigation into job competitiveness enhanced by acquiring foreign language proficiency - Taking the Beijing - based enterprises as example. Journal of Changchun Normal University, 30(6). 163-166. In Chinese.

McManus, W., Gould, W., \& Welch, F. (1983). Earnings of Hispanic men: The role of English language proficiency. Journal of Labor Economics, 1, 101-130. https://doi.org/10.1086/298006

Meng, D. H., Su, L. F., \& Shi, L. L. (2012). An overview of literature for human capital and social capital impact on employment of college students. Economic Perspectives, 1, 86-90. In Chinese.

Meyer, R. H., \& Wise, D. A. (1979). High school preparation and early labor force experience. National Bureau of Economic Research. https://doi.org/10.3386/w0342

Neamțu, D. (2012). Education - an investment in human capital. Journal of Economics and Business Research, 2, $150-160$.

Nong, X. M. (2009). Evaluating the "English Craze" from social psychology and linguistic economic perspective. Guangxi Social Science, 8. In Chinese.

Piche, V., Renaud, J., \& Gingras, L. (1999). Comparative immigrant economic integration. Immigrant Canada. 
Demographic, economic, and social challenges, 185-211. https://doi.org/10.3138/9781442676022-011

Potestio, P. (2011). The Employment of Young Graduates in the Period 2000-2010: A Comparison between Six European Countries. Modern Economy, 2(5), 880. https://doi.org/10.4236/me.2011.25099

Qiao, Z. H. Song, H. T., Feng, M. L., \& Shao, Y. P. (2011). Research on human capital, social capital and employment of Chinese college graduates. Chinese Youth Research, 4, 24-28.

Riddell, W. C., \& Song, X. (2011). The impact of education on unemployment incidence and re-employment success: Evidence from the U.S. labor market. Labor Economics, 18(4), 453-463. https://doi.org/10.1016/j.labeco.2011.01.003

Rotkowski, J. (2003). Rapid Labor Reallocation with a Stagnant Unemployment Pool: The Puzzle of the Labor Market in Lithuania. Policy Research Working Paper, No. 2946. World Bank, Washington, DC. https://doi.org/10.1596/1813-9450-2946

Sagen, H. B., Dallam, J. W., \& Laverty, J. R. (2000). Effects of career preparation experiences on the initial employment success of college graduates. Research in Higher Education, 41(6), 753-767. https://doi.org/10.1023/A:1007072705601

Saito, H., \& Wu, J. (2016). Agglomeration, congestion, and U.S. regional disparities in employment growth. Journal of Regional Science, 56(1), 53-71. https://doi.org/10.1111/jors.12204

Schultz, T. W. (1963). The economic value of education. New York: Columbia University Press.

Schultz, W. T. (1961). Investment in Human Capital: An Economic Viewpoint. The American Economic Review, $51(1)$.

Shields, M. A., \& Wheatley Price, S. (2002). The English language fluency and occupational success of ethnic minority immigrant men living in English metropolitan areas. Journal of Population Economics, 15(1), 137-160. https://doi.org/10.1007/PL00003836

Smith, A. (1776). The wealth of nations. University of Chicago Edition.

Stanfield, J. (2009). The profit motive in education. Economic Affairs, 29, 90. https://doi.org/10.1111/j.1468-0270.2009.01906.x

Tainer, E. (1988) English language proficiency and earnings among foreign born men. Journal of Human Resources, 23(1), 108-122. https://doi.org/10.2307/145847

Thomsen, S. L., Gernandt, J., \& Aldashev, A. (2009). Language usage, participation, employment and earnings: Evidence for foreigners in West Germany with multiple sources of selection. Labor Economics, 16(3), 330-341. https://doi.org/10.1016/j.labeco.2008.11.004

Toussaint-Comeau, M. (2006). The occupational assimilation of Hispanic immigrants in the U.S.: Evidence from panel data. International Migration Review, 40(3), 508-536. https://doi.org/10.1111/j.1747-7379.2006.00034.x

Vaillancourt, F. (1982). The economics of language and language planning, Language Problems and Language Planning, 7(2), 162-178. http://dx.doi.org/10.1075/1plp.7.2.04vai

Waldorf, B. S., Beckhusen, J., Florax, R. J. G. M., \& De Graaff, T. (2010). The role of human capital in language acquisition among immigrants in US metropolitan. Regional Science Policy \& Practice, 2(1), 39-49. https://doi.org/10.1111/j.1757-7802.2010.01019.x

Wang, H., Smyth, R., \& Cheng, Z. (2017). The economic returns to proficiency in English in China. China Economic Review, 43, 91-104. https://doi.org/10.1016/j.chieco.2017.01.004

Wang, X. J. (2015). Effects analysis on human capital of language. China Collective Economy, Vol. 13. In Chinese.

Yin, X. (2010). Research on foreign trade English education based on human capital theory of language economics. Journal of Suzhou University, 25(9), 117-119. In Chinese.

Yue, C. J., Wen, D. M., \& Ding, X. H. (2004). Employment and first salary: empirical analysis on employment competition for college graduates. Management World, 11, 53-61. In Chinese.

Zein, M. S. (2017). Professional development needs of primary EFL teachers: Perspectives of teachers and teacher educators. Professional Development in Education, 43(2), 293-313. https://doi.org/10.1080/19415257.2016.1156013 
Zhang, J. L. (2014). Reflection of foreign language education by researching on language skill being human capital. Journal of Chongqing University of Education, 27(1), 144-146. In Chinese.

Zhao, Y. L. (2004). Analysis on the relationship between college students' English proficiency and employment competitiveness. Higher Education in China, 7. In Chinese.

Zhu, Q., \& Wang, L. (2016, August 26). The international labor organization reports that the number of youth unemployed worldwide will increase by half a million this year. China Daily. Retrieved from: http://world.chinadaily.com.cn/2016-08/26/content_26605661.htm. In Chinese.

\section{Copyrights}

Copyright for this article is retained by the author(s), with first publication rights granted to the journal.

This is an open-access article distributed under the terms and conditions of the Creative Commons Attribution license (http://creativecommons.org/licenses/by/4.0/). 